\begin{tabular}{|c|l|}
\hline Title & $\begin{array}{l}\text { Construction of Mono- and Multimolecular Layers with Electron Transfer Mediation Function and Catalytic A ctivity } \\
\text { for Hydrogen Evolution on a Hydrogen-Terminated Si (111) Surface via Si - C Bond }\end{array}$ \\
\hline Author(s) & Masuda, Takuya; Shimazu, Katsuaki; U osaki, Kohei \\
\hline Citation & $\begin{array}{l}\text { Journal of Physical Chemistry C, 112(29), 10923-10930 } \\
\text { https:/doi.org/10.1021/p8006188 }\end{array}$ \\
\hline Issue Date & 2008-07-24 \\
\hline Doc URL & http://hdl.handle.net/2115/50214 \\
\hline Type & article \\
\hline File Information & JPCC112-29_10923_10930.pdf \\
\hline
\end{tabular}

Instructions for use 


\title{
Construction of Mono- and Multimolecular Layers with Electron Transfer Mediation Function and Catalytic Activity for Hydrogen Evolution on a Hydrogen-Terminated Si(111) Surface via $\mathrm{Si}-\mathrm{C}$ Bond
}

\author{
Takuya Masuda, Katsuaki Shimazu, ${ }^{\dagger}$ and Kohei Uosaki* \\ Physical Chemistry Laboratory, Division of Chemistry, Graduate School of Science, Hokkaido University, \\ Sapporo 060-0810, Japan
}

Received: January 22, 2008; Revised Manuscript Received: April 23, 2008

\begin{abstract}
Organic molecular layers with viologen moiety (i.e., electron acceptor) were constructed on a hydrogenterminated $\mathrm{Si}(111)$ surface via a $\mathrm{Si}-\mathrm{C}$ bond. Electrochemical characteristics after each synthetic process were measured, and electron mediation capability of the viologen moiety was demonstrated. Incorporation of platinum particles on the viologen-modified $\mathrm{Si}(111)$ surface was proved to enhance the hydrogen evolution reaction (HER) rate. Further improvement of the HER rate was achieved by the modification with viologen/ Pt multilayers. Photoelectrochemical HER at the p-Si(111) electrode was also significantly accelerated by the modification with mono- and multiviologen/Pt layers.
\end{abstract}

\section{Introduction}

Construction of molecular layers on solid surfaces has attracted much attention not only because it is important from a fundamental science point of view but also because it is a key technique for a wide range of applications such as molecular and biomolecular electronic devices, catalysis, and sensors.

Although the most studied molecular layer system is selfassembled monolayers (SAMs) of alkanethiols on various metals, especially on gold, ${ }^{1-9}$ ordered molecular layers with various functionalities on semiconductor, particularly $\mathrm{Si}$, surfaces should be more important for technological applications. For example, a monolayer with electron transfer function on $\mathrm{Si}$ is very important as far as the application for molecular devices, ${ }^{10}$ sensors,${ }^{11}$ photoelectrochemistry, ${ }^{12-15}$ bioelectrochemistry, ${ }^{16}$ and electrocatalysis ${ }^{13-15}$ are concerned. Organic monolayer can be formed on $\mathrm{Si}$ surface via direct $\mathrm{Si}-\mathrm{C}$ bond utilizing thermal, ${ }^{17-23}$ photochemical, ${ }^{24,25}$ electrochemical, ${ }^{26-28}$ or catalytic reaction ${ }^{28,29}$ or reaction with radical initiators. $18,27,31,32$ We investigated the organic monolayer formation process on a hydrogen-terminated $\mathrm{Si}(111)$ by using attenuated total reflectance Fourier transform infrared (ATR FT-IR) and sum frequency generation spectroscopy $^{21}$ and also found that organic monolayers formed on $\mathrm{Si}(111)$ surfaces are in a relatively high conformational order as alkanethiol SAMs on $\mathrm{Au}(111) .^{23}$

Both theoretical and experimental understandings of photoelectrochemical/photocatalytic reactions at semiconductor surfaces have been significantly progressed in the past 30 years because of the interest in solar energy conversion. ${ }^{33,34}$ Photoinduced water splitting at the semiconductor surface is the most important photoelectrochemical/photocatalytic process to construct a highly efficient and stable solar energy conversion/ storage system. ${ }^{35}$ One of the most critical issues is that the semiconductor surface is usually not suitable for multielectron

* To whom correspondence should be addressed. Phone: +81-11-7063128. Fax: +81-11-706-3440. E-mail: uosaki@pcl.sci.hokudai.ac.jp.

$\dagger$ Group of Functional Materials Chemistry, Section of Environmental Materials Science, Faculty of Environmental Earth Science, Hokkaido University, Sapporo 060-0810, Japan. processes such as oxidation and reduction of water, and appropriate catalysts are required to drive these processes efficiently.

Although many groups reported that p-type semiconductor electrodes coated with thin noble metal layers efficiently generated hydrogen under illumination, ${ }^{36-38}$ modification of a semiconductor surface with a continuous metallic layer often resulted in a low efficiency because of the semiconductor/metal Schottky barrier formation. ${ }^{39,40}$ It was suggested that the modification with discontinuous metallic islands (i.e., nanoparticles) has an advantage for photoelectrochemical hydrogen evolution reaction (HER) because the barrier height of a semiconductor/metal junction can be controlled by the size and density of the metal nanoparticles. ${ }^{37,41-47}$ Unfortunately, however, this approach has several problems. Photoelectrochemical efficiency of the electrode was degraded because of lower coverage of the metal layer and, furthermore, the modification of semiconductor surface with discontinuous metal also sometimes leads to a significant loss of photoelectrochemical HER current because the metal acts as a recombination center. ${ }^{48,49}$ To provide a solution to these problems, various groups used polymer layers with electron mediator groups and catalytic metal particles to modify the semiconductor surfaces..$^{50-59}$

Recently, we briefly demonstrated that an organic monolayer with viologen terminal group bonded on hydrogen-terminated n- and p-type $\mathrm{Si}(111)$ surfaces via a $\mathrm{Si}-\mathrm{C}$ bond acted as electron transfer mediator and improved the electrochemical hydrogen evolution reaction rate in the dark and under illumination, respectively. ${ }^{60}$ Nakato and colleagues also showed that the stability of the Si photoelectrode for $\mathrm{I}^{-}$oxidation was improved by Pt/alkyl monolayer modification. ${ }^{13,14}$

Here, we investigated in detail the construction processes of organic monolayers with viologen moiety, not only with a monoviologen layer but also with multiviologen layers, on nand p-type $\mathrm{Si}(111)$ electrodes and the electrochemical characteristics of the modified $\mathrm{n}$ - and $\mathrm{p}-\mathrm{Si}(111)$ electrodes in the dark and under illumination, respectively. After each modification step, surfaces were characterized by XPS, ellipsometry, and ATR FT-IR, and electrochemical characteristics were measured. Electron mediation capability of "wired" viologen moieties was 
SCHEME 1: Steps for Construction of a Viologen Layer on $\mathrm{H}-\mathrm{Si}(111)\left(\mathrm{V}^{2+}-\mathrm{Si}(111)\right)$ and Deposition of Pt $\left(\mathbf{P t}-\mathrm{V}^{2+}-\mathrm{Si}(111)\right)$

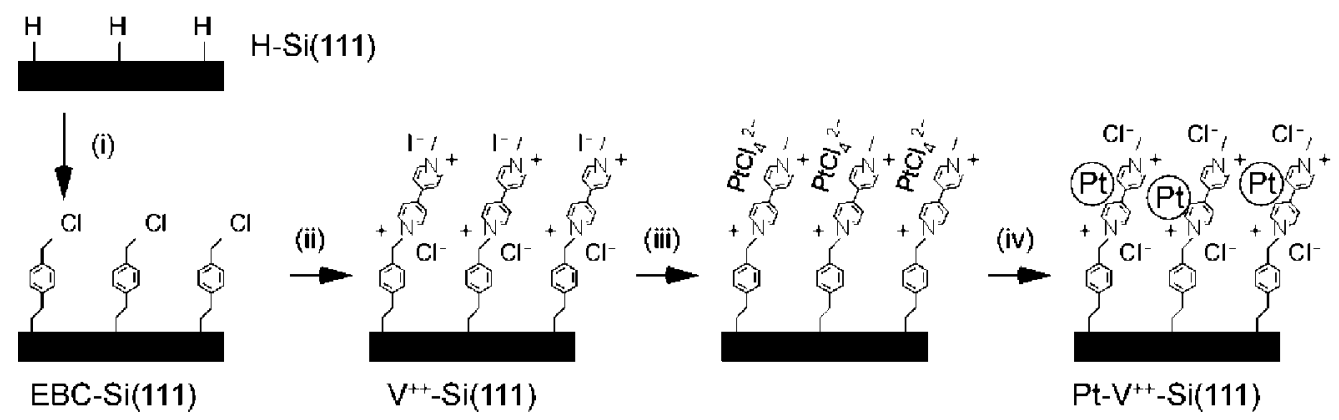

SCHEME 2: Steps for Construction of a Triethylbenzylammonium Chloride Terminated Layer on $\mathrm{H}-\mathrm{Si}(111)$ (EBTEA-Si(111)) and Deposition of Pt (Pt-EBTEA-Si(111))

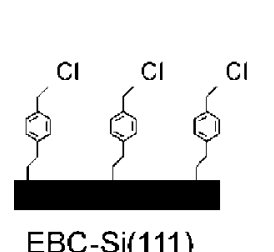

EBC-Si(111)

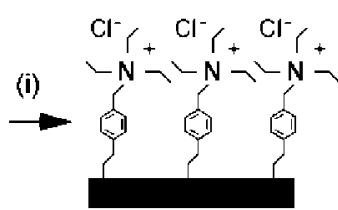

EBTEA-Si(111)
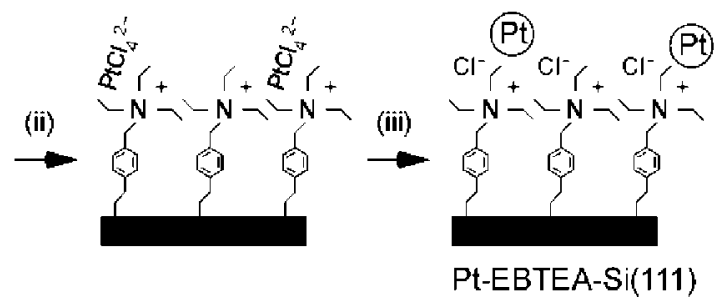

demonstrated, and significant enhancement of the (photo)electrochemical hydrogen evolution reaction rate was achieved by incorporating Pt particles at the mono- and multiviologen layer modified Si(111) surface.

\section{Experimental Section}

Materials. Ultrapure nitrogen (99.9995\%) and argon (99.999\%) were purchased from Air-Water. Ultrapure-grade sulfuric acid and potassium chloride and reagent-grade sodium sulfate, hydrochloric acid, hydrofluoric acid, hydrogen peroxide, benzene, ethanol, potassium tetrachloroplatinate(II), 1-bromobutane and 1,4-dibromobutane, triethylamine (TEA), 4-vinylbenzylchloride (4VBC), 1-decene, and 4, 4'-bipyridine from Aldrich, methyl iodide from Tokyo Kasei, ultrapure-grade methylene chloride (dichloromethane), dimethyl form amide from Dojin laboratory, and special grade (for semiconductor industries) ammonium fluoride from Morita Chemical were used as received except for $4 \mathrm{VBC}$, which was purified by vacuum distillation before use. Water was purified using a Milli-Q system (Yamato, WQ-500). Ag (99.99\%) and Pt wires $(99.99 \%)$ were purchased from Nilaco.

Double-side polished Si(111) single-crystal wafers of $100 \mathrm{~mm}$ in diameter, $480 \mu \mathrm{m}$ in thickness, and resistivity of $1-10 \Omega$ cm (n-type; phosphorus-doped, p-type; boron-doped) were donated by Shin-Etsu Semiconductor. The silicon wafers were treated as follows immediately before using. Si wafers were cleaned with acetone and then with Milli-Q water several times in an ultrasonic bath for 5 min each time. Silicon substrates for the electrochemical and the X-ray photoelectron spectroscopic measurements were square $\left(10 \times 10 \mathrm{~mm}^{2}\right)$. Parallelogram ATR prisms $\left(28 \times 35 \times 0.48 \mathrm{~mm}^{3}\right)$ were prepared by cutting and polishing with $45^{\circ}$ bevels. ${ }^{22}$

The Si(111) substrate was cleaned by sequential immersion of the sample in freshly prepared sulfuric acid and hydrogen peroxide ( $2: 1$ by volume) at $60{ }^{\circ} \mathrm{C}$ for $20 \mathrm{~min}$, in an aqueous solution of $0.5 \%$ hydrofluoric acid at room temperature (RT) for $5 \mathrm{~min}$ and in freshly prepared RCA solution (water/hydrogen peroxide/hydrochloric acid, $4: 1: 1$ by volume) at $80{ }^{\circ} \mathrm{C}$ for 20 min. After these treatments, the sample was immersed in deaerated aqueous solution of $40 \%$ ammonium fluoride for 5 min to obtain a monohydride-terminated surface, $\mathrm{H}-\mathrm{Si}(111) .{ }^{61,62}$

Synthesis. 1-Methyl-4-(4'-pyridyl)-pyridinium iodide (MQ) was synthesized by refluxing 4,4'-bipyridine and methyl iodide in benzene under Ar atmosphere overnight. An orange solid was precipitated from solution after cooling. The solution was filtered to collect the orange solid, followed by washing with benzene and hexane. The solid was dissolved in acetonitrile and filtered to remove any insoluble product. Acetonitrile was removed by evaporation to yield the desired product. ${ }^{63}$ Structure and purity of the product were confirmed by nuclear magnetic resonance.

Formation of Molecular Layers. Monoviologen-layer formation was performed as shown in Scheme $1 .^{60} \mathrm{~A}$ freshly prepared $\mathrm{H}-\mathrm{Si}(111)$ substrate was illuminated with 254-nm light $\left(\sim 1 \mathrm{~mW} \mathrm{~cm}^{-2}\right)$ for $24 \mathrm{~h}$ in deaerated $4 \mathrm{VBC}$ in the Ar-filled glovebox to yield a 4-ethylbenzylchloride (EBC)-modified Si(111) surface (Scheme 1, step i), The substrate was then rinsed with deaerated dichloromethane followed by sonication in dichloromethane for 10 min twice. The EBC-Si(111) substrate was kept in MQ-saturated DMF solution at $100{ }^{\circ} \mathrm{C}$ under $\mathrm{Ar}$ atmosphere for $20 \mathrm{~h}$ to yield a viologen-modified $\left(\mathrm{V}^{2+}\right) \mathrm{Si}(111)$ surface (Scheme 1, step ii).

TEA, which is an electroinactive species, was also attached to the EBC-Si(111) surface as shown in Scheme 2. The EBC-Si(111) substrate was refluxed in TEA under Ar atmosphere for $20 \mathrm{~h}$ to yield a (4-ethylbenzyl)triethylammonium chloride-modified (EBTEA) $\mathrm{Si}(111)$ surface (Scheme 2, step i).

1-Decene was reacted with $\mathrm{H}-\mathrm{Si}(111)$ in neat 1-decene at reflux temperature for $50 \mathrm{~h}$ to yield a decyl-modified $\mathrm{Si}(111)$ surface $(\mathrm{C} 10-\mathrm{Si}(111))$.

Multiviologen-layer was formed as shown in Scheme 3. The EBC-Si(111) substrate was kept in a 4,4'-bipyridine-saturated benzene solution at reflux temperature under Ar atmosphere for $12 \mathrm{~h}$ (Scheme 3, step i). The substrate was placed in 1,4- 
SCHEME 3: Steps for Construction of a Multiviologen Layer on $\mathrm{H}-\mathrm{Si}(111)\left(\mathrm{V}^{2+}-\mathrm{Si}(111)\right)$ and Deposition of $\mathrm{Pt}$ $\left(\mathbf{P t}-\mathrm{V}^{2+}-\mathrm{Si}(\mathbf{1 1 1})\right)$
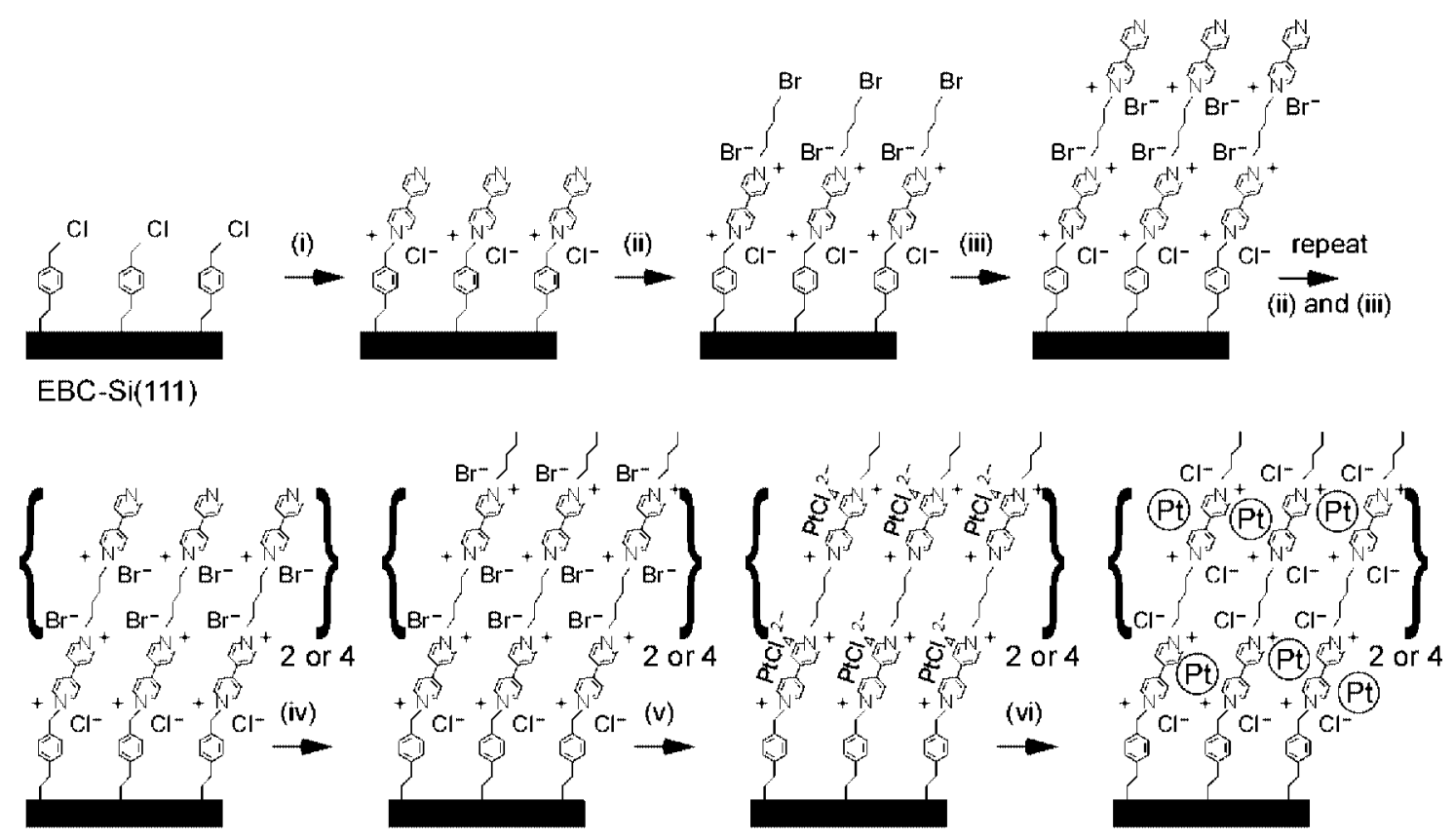

$3 \mathrm{~L}$ or $5 \mathrm{LPt}-\mathrm{V}^{++}-\mathrm{Si}(111)$

dibromobutane under $\mathrm{Ar}$ atmosphere at $100^{\circ} \mathrm{C}$ for $12 \mathrm{~h}$ (Scheme 3 , step ii) then in 4,4'-bipyridine-saturated benzene solution at reflux temperature for $12 \mathrm{~h}$ (Scheme 3, step iii). After repeating the modification steps ii and iii alternately for 2 or 4 times so that the monolayer was terminated with bipyridine group, the substrate was kept in 1-bromobutane under Ar atmosphere at $100{ }^{\circ} \mathrm{C}$ for $12 \mathrm{~h}$ to yield a $3 \mathrm{~L}-$ or $5 \mathrm{~L}-\mathrm{V}^{2+}-\mathrm{Si}(111)$ surface (Scheme 3, step iv). The Si(111) substrates after each modification step were rinsed with water, ethanol, and dichloromethane.

Pt Modification of $\mathrm{V}^{2+}-, 3 \mathrm{~L}-\mathrm{V}^{2+}-, 5 \mathrm{~L}-\mathrm{V}^{2+}-$, and EBTEA-Si(111) Surface. Pt modification was performed following the procedure reported before as shown in Schemes $1-3 .{ }^{54-59}$ The $\mathrm{V}^{2+}-$ or EBTEA-Si(111) substrate was placed in a $10 \mathrm{mM} \mathrm{K} \mathrm{PtCl}_{4}$ aqueous solution for $10 \mathrm{~min}$ to ion exchange the halide ions of the viologen groups (Scheme 1, step iii) or EBTEA (Scheme 2, step ii) by $\mathrm{PtCl}_{4}{ }^{2-}$. $\mathrm{PtCl}_{4}{ }^{2-}$ was reduced to $\mathrm{Pt}$ to yield a $\mathrm{Pt}-\mathrm{V}^{2+}-\mathrm{Si}(111)$ (Scheme 1, step iv) or Pt-EBTEA-Si(111) surface (Scheme 2, step iii) by keeping the substrate in a $\mathrm{H}_{2}$-saturated water for $20 \mathrm{~min}$. Because there is a possibility that $\mathrm{V}^{2+}$ was reduced to $\mathrm{V}^{\bullet+}$ during the reduction of $\mathrm{PtCl}_{4}{ }^{2-}$, the $\mathrm{Pt}-\mathrm{V}^{2+}-\mathrm{Si}(111)$ substrate was immersed in an aqueous solution of $0.1 \mathrm{M} \mathrm{HCl}$ for $30 \mathrm{~s}$ to reoxidize $\mathrm{V}^{\bullet+}$ to $\mathrm{V}^{2+} .56$

The $3 \mathrm{~L}$ or $5 \mathrm{~L}^{-} \mathrm{V}^{2+}-\mathrm{Si}(111)$ substrate was immersed in an aqueous solution of $10 \mathrm{mM} \mathrm{K}_{2} \mathrm{PtCl}_{4}$ for $20 \mathrm{~min}$ to ion exchange the halide ions of the viologen groups by $\mathrm{PtCl}_{4}{ }^{2-}$ (Scheme 3 , step v). The substrate was placed in $\mathrm{H}_{2}$-saturated water for 20 min so that $\mathrm{PtCl}_{4}{ }^{2-}$ was reduced to $\mathrm{Pt}$ to yield a $3 \mathrm{~L}-$ or $5 \mathrm{~L}-$ $\mathrm{Pt}-\mathrm{V}^{2+}-\mathrm{Si}(111)$ substrate (Scheme 3, step vi).

X-ray Photoelectron Spectroscopy. X-ray photoelectron spectra (XP spectra) were obtained using a Rigaku model XPS7000 X-ray photoelectron spectrometer with monochromic $\mathrm{Mg}$ $\mathrm{K} \alpha$ radiation at $25-300 \mathrm{~W}$. Photoelectrons were collected at $0^{\circ}$ from the surface normal (i.e., takeoff angle of $90^{\circ}$ ).

ATR FT-IR. ATR FT-IR spectra were obtained using a BioRad FTS-30 spectrometer equipped with a mercury cadmium telluride ( $\mathrm{HgCdTe}$ ) detector cooled with liquid nitrogen. All the spectra were measured in p-polarization by integrating 256 interferrograms with a resolution of $2 \mathrm{~cm}^{-1}$, and a spectrum of an oxidized $\mathrm{Si}(111)$ surface was used as a reference.

Ellipsometry. Ellipsometric measurements were carried out with a SOPRA GESP 5 spectrometer using a $30 \mathrm{~W}$ Xe lamp as a light source. The incident angle was set at $75^{\circ}$. The $\Psi$ and $\Delta$ values were measured between 300 and $800 \mathrm{~nm}$ with a step of $10 \mathrm{~nm}$. Simulations were carried out using software provided by the manufacturer (SOPRA, WinElli) as follows. ${ }^{64-66}$ The complex dielectric function for $\mathrm{Si}(111)$ substrate was determined using hydrogen-terminated $\mathrm{Si}(111)$ substrate. The dielectric functions for EBC and viologen layers were postulated to have no imaginary parts and to be the same as those of the polystyrene, $1.59,{ }^{67}$ based on the assumption that the EBC and viologen layers have negligibly small absorption in the 300-800 $\mathrm{nm}$. The thickness of the EBC, $\mathrm{V}^{2+}, 3 \mathrm{~L}-\mathrm{V}^{2+}$, and $5 \mathrm{~L}-\mathrm{V}^{2+}$ layers were determined by iterative fitting procedures.

SEM. Scanning electron microscopic (SEM) images were obtained using a Hitachi ultrahigh resolution scanning electron microscope S-5200. The samples were mounted on samples fixed by double side adhesive carbon tape. The SEM measurements were performed at an accelerating voltage of $25 \mathrm{kV}$.

Electrochemistry. Electrochemical measurements in the dark and under illumination were performed in a $0.1 \mathrm{M} \mathrm{Na}_{2} \mathrm{SO}_{4}$ aqueous solution using a three-electrode photoelectrochemical cell. $\mathrm{A} \mathrm{Ag} / \mathrm{AgCl}$ electrode and a Pt wire were used as a reference and a counter electrodes, respectively. A potentiostat (Hokuto Denko, HA-501G) was used to control the electrode potential of working electrode, and a function generator (Hokuto Denko, HB-111) was used to provide an external potential to obtain cyclic voltammograms (CVs), which were recorded with an X-Y recorder (Graphtec, WX-1200). A $500 \mathrm{~W}$ xenon lamp (Ushio, UXL-500-D) through an IR cut filter (Toshiba, IRA-20) and a UV cut filter (Sigma Koki) was used for photocurrent measurements. Irradiated light intensity was $40 \mathrm{~mW} \mathrm{~cm}^{-2}$ as determined by optical power meter (Melles Griot). 


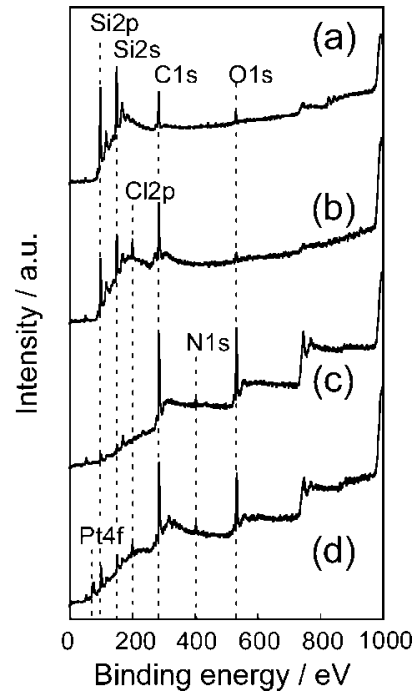

Figure 1. Wide-scan XP spectra of the (a) $\mathrm{H}-\mathrm{Si}(111)$, (b) $\mathrm{EBC}-\mathrm{Si}(111)$, (c) $\mathrm{V}^{2+}-\mathrm{Si}(111)$, and (d) $\mathrm{Pt}-\mathrm{V}^{2+}-\mathrm{Si}(111)$ surfaces.

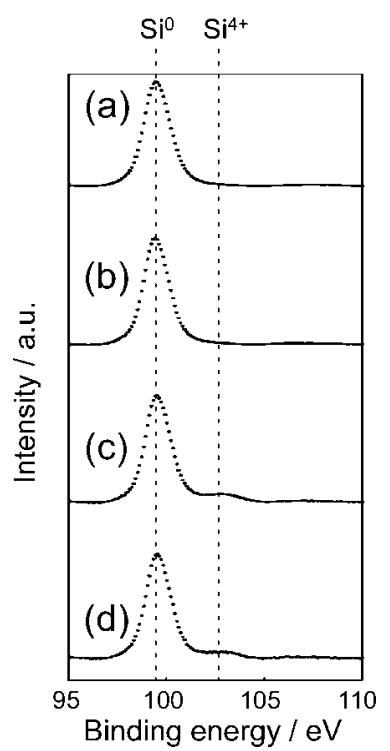

Figure 2. XP spectra in the $\mathrm{Si} 2 \mathrm{p}$ region of the (a) $\mathrm{H}-\mathrm{Si}(111)$, (b) $\mathrm{EBC}-\mathrm{Si}(111)$, (c) $\mathrm{V}^{2+}-\mathrm{Si}(111)$, and (d) $\mathrm{Pt}-\mathrm{V}^{2+}-\mathrm{Si}(111)$ surfaces.

\section{Results and Discussion}

Formation and Characterization of Molecular Layers. Figures 1 and 2 show XP spectra of wide scan and narrow scan in $\mathrm{Si} 2 \mathrm{p}$ region, respectively, of (a) $\mathrm{H}-\mathrm{Si}(111)$, (b) $\mathrm{EBC}-\mathrm{Si}(111)$, (c) $\mathrm{V}^{2+}-\mathrm{Si}(111)$, and (d) $\mathrm{Pt}-\mathrm{V}^{2+}-\mathrm{Si}(111)$ surfaces, and Figure 3 shows ATR FT-IR spectra of (a) H-Si(111), (b) EBC-Si(111), and (c) $\mathrm{V}^{2+}-\mathrm{Si}(111)$ surfaces in the regions of $2200-2000$ and $3200-2800 \mathrm{~cm}^{-1}$.

$\boldsymbol{H}$-Si(111) Surface. The wide-scan XP spectra (Figure 1a) showed peaks corresponding to $\mathrm{Si} 2 \mathrm{p}, \mathrm{Si} 2 \mathrm{~s}, \mathrm{C} 1 \mathrm{~s}$, and $\mathrm{O} 1 \mathrm{~s}$ around $100,150,285$, and $530 \mathrm{eV}$, respectively, ${ }^{68}$ and no other peaks corresponding to elements such as fluorine at the $\mathrm{H}-\mathrm{Si}(111)$ surface. The $\mathrm{C} 1 \mathrm{~s}$ and $\mathrm{O} 1 \mathrm{~s}$ peaks should be due to the surface contamination. Only a peak corresponding to $\mathrm{Si}^{0}$ at $99.4 \mathrm{eV}$ was observed in the XP spectra in the Si 2 p region (Figure $2 a$ ). The absence of a peak due to $\mathrm{Si}^{4+}$ around $103 \mathrm{eV}$ shows that the surface was not oxidized. ${ }^{68}$ In the ATR FT-IR spectrum of the $\mathrm{H}-\mathrm{Si}(111)$ surface (Figure 3a), a very sharp peak at 2084 $\mathrm{cm}^{-1}$ corresponding to the stretching vibration of the monohydride on a $\mathrm{Si}(111)$ surface $^{62}$ and no other bands related to the

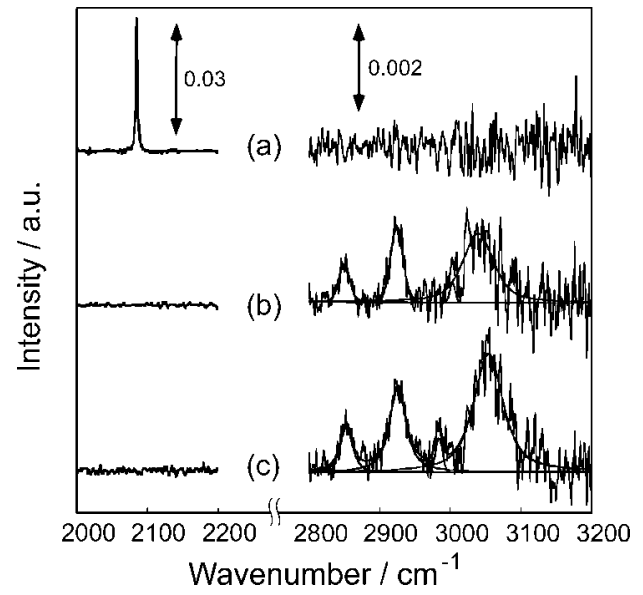

Figure 3. ATR FT-IR spectra of the (a) $\mathrm{H}-\mathrm{Si}(111)$, (b) EBC-Si(111), and $(c) \mathrm{V}^{2+}-\mathrm{Si}(111)$ surfaces in the regions of $2200-2000$ and $3200-2800 \mathrm{~cm}^{-1}$.

dihydride or trihydride were observed in the $\mathrm{Si}-\mathrm{H}$ (2200-2000 $\mathrm{cm}^{-1}$ ) stretching vibration region, confirming that an atomically flat $\mathrm{Si}(111)$ surface terminated by an extremely homogeneous monolayer of monohydride was obtained as previously reported. ${ }^{62}$ No bands corresponding to organic adsorbate were observed in the $\mathrm{C}-\mathrm{H}\left(3200-2800 \mathrm{~cm}^{-1}\right)$ stretching vibration region.

EBC-Si(111) Surface. After the EBC modification (step i in Scheme 1), the $\mathrm{C} 1 \mathrm{~s}$ peak at $285 \mathrm{eV}$ became stronger and the $\mathrm{Cl} 2 \mathrm{p}$ peak at $200 \mathrm{eV}$ appeared in a wide-scan XP spectrum (Figure 1b). A peak corresponding to $\mathrm{Si}^{0}$ at $99.4 \mathrm{eV}$ was observed and a peak due to $\mathrm{Si}^{4+}$ around $103 \mathrm{eV}$ was absent in the XP spectra in the $\mathrm{Si} 2 \mathrm{p}$ region (Figure $2 \mathrm{~b}$ ). In the ATR FT-IR spectrum of the EBC-Si(111) surface (Figure $3 b$ ), the $\mathrm{Si}-\mathrm{H}$ peak disappeared and two bands at 2852 and $2923 \mathrm{~cm}^{-1}$ corresponding to the $\mathrm{C}-\mathrm{H}$ stretching vibration of the symmetric and asymmetric methylene group, respectively, and a broad band between 3000 and $3100 \mathrm{~cm}^{-1}$ corresponding to the $\mathrm{C}-\mathrm{H}$ stretching vibration of benzene ring were observed. These results support the formation of the EBC layer on the Si(111) surface via $\mathrm{Si}-\mathrm{C}$ covalent bond without any $\mathrm{Si}$ oxide layer. Ellipsometric thickness of the EBC layer was determined to be 1.1 $\mathrm{nm}$, which is in good agreement with the molecular length of 4-ethylbenzylchloride.

Attachment of a Viologen Group to the EBC-Si(111) Surface and Formation of a Multiviologen Layer. After the modification step ii of Scheme 1 (i.e., $\mathrm{V}^{2+}-\mathrm{Si}(111)$ ), a widescan XP spectrum (Figure 1c) shows the significant decrease of Si2s and Si2p peaks and a new peak around $402 \mathrm{eV}$ corresponding to N1s. A small $\mathrm{Si}^{4+}$ peak was observed in the $\mathrm{Si} 2 \mathrm{p}$ region (Figure $2 \mathrm{c}$ ), implying the formation of a thin $\mathrm{Si}$ oxide layer at this modification step. In the ATR FT-IR spectrum of the $\mathrm{V}^{2+}-\mathrm{Si}(111)$ surface (Figure 3c), intensity of the broad band due to the $\mathrm{C}-\mathrm{H}$ stretching vibration of the benzene ring increased and a new band at $2983 \mathrm{~cm}^{-1}$ corresponding to the $\mathrm{C}-\mathrm{H}$ stretching vibration of the asymmetric methyl group was observed. These results confirm the attachment of viologen to the EBC layer on the $\mathrm{Si}(111)$ surface.

Ellipsometric thickness of the $\mathrm{V}^{2+}, 3 \mathrm{~L}-\mathrm{V}^{2+}$, and $5 \mathrm{~L}-\mathrm{V}^{2+}$ layers were determined to be $2.8,5.6$, and $8.6 \mathrm{~nm}$, respectively, as shown by filled circles in Figure 7(b). These values are in good agreement with those evaluated from the sums of lengths of molecules in the respective molecular layers.

Attachment of the Triethylamine Group to the EBC-Si(111) Surface. There is no remarkable difference in features of the wide-scan XP spectrum of the EBTEA-Si(111) surface (after 


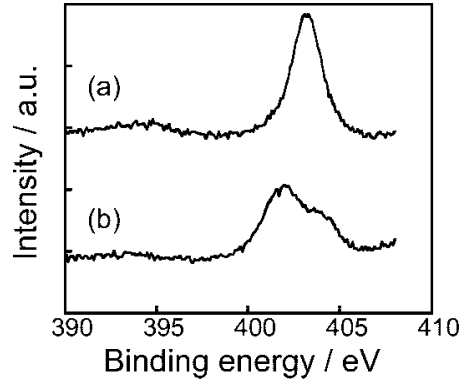

Figure 4. $\mathrm{XP}$ spectra in the $\mathrm{N} 1 \mathrm{~s}$ region of the (a) EBTEA-Si(111) and (b) $\mathrm{V}^{2+}-\mathrm{Si}(111)$ surfaces.

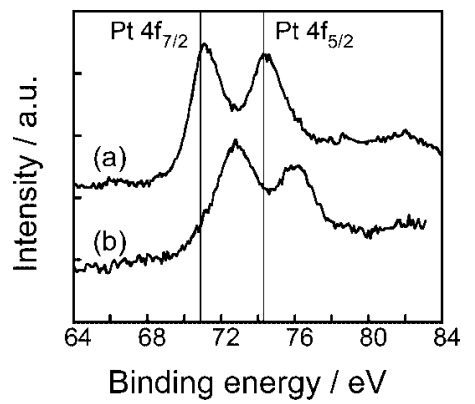

Figure 5. XP spectra in the $\mathrm{Pt} 4 \mathrm{f}$ region of the (a) Pt-EBTEA-Si(111) and (b) $\mathrm{Pt}-\mathrm{V}^{2+}-\mathrm{Si}(111)$ surfaces.

step i in Scheme 2) and that of the $\mathrm{V}^{2+}-\mathrm{Si}(111)$ surface except for shapes of those in the $\mathrm{N}$ 1s region. While a narrow-scan $\mathrm{XP}$ spectrum in the $\mathrm{Si} 2 \mathrm{p}$ region of the EBTEA-Si(111) surface (not shown) is similar to that of the $\mathrm{V}^{2+}-\mathrm{Si}(111)$ surface, $\mathrm{XP}$ spectra in the $\mathrm{N}$ 1s region of the (a) EBTEA- and (b) $\mathrm{V}^{2+}-\mathrm{Si}(111)$ surfaces are somewhat different, as shown in Figure 4. Although a single peak at $402.2 \mathrm{eV}$ corresponding to nitrogen of benzyltriethylammonium chloride was observed at the EBTEA-Si(111) surface (Figure 4a), two peaks around 400.2 and $402.0 \mathrm{eV}$ corresponding to nitrogen species of pyridinium iodide and chloride, respectively, were observed at the $\mathrm{V}^{2+}-\mathrm{Si}(111)$ surface (Figure $4 \mathrm{~b}$ ).

Incorporation of Pt. Pt $4 \mathrm{f}$ peak was observed around $70 \mathrm{eV}^{68}$ in the wide-scan XP spectrum obtained after step iv in Scheme $1\left(\mathrm{Pt}-\mathrm{V}^{2+}-\mathrm{Si}(111)\right.$, Figure 1d) and that obtained after step iii in Scheme 2 (Pt-EBTEA-Si(111), not shown), confirming the presence of Pt on both surfaces. Figure 5 shows the XP spectra in the $\mathrm{Pt} 4 \mathrm{f}$ region of the (a) Pt-EBTEA- and (b) $\mathrm{Pt}-\mathrm{V}^{2+}-\mathrm{Si}(111)$ surfaces. Two peaks at lower and higher binding energy are assigned to be due to $\mathrm{Pt} 4 \mathrm{f}_{7 / 2}$ and $\mathrm{Pt} 4 \mathrm{f}_{5 / 2}$, respectively, and the positions of the $\mathrm{Pt}_{4} \mathrm{f}_{7 / 2}(70.9 \mathrm{eV})$ and $\mathrm{Pt}$ $4 \mathrm{f}_{5 / 2}(74.3 \mathrm{eV})$ peaks observed for bulk metallic platinum are marked by solid lines. Although the positions of $\mathrm{Pt} 4 \mathrm{f}$ peaks of the Pt-EBTEA-Si(111) surface are similar to those of the bulk metallic Pt, Pt 4f peaks of the $\mathrm{Pt}-\mathrm{V}^{2+}-\mathrm{Si}(111)$ surface are observed at higher binding energy by ca. $2 \mathrm{eV}$ than those of the bulk metallic Pt. A similar shift was reported for small metal clusters because of a slow relaxation of the core hole created by photoemission, due to the small size of the clusters and the poor interaction between the deposited metal and substrate. ${ }^{69}$ This result suggests that very small Pt nanoparticles were formed at the $\mathrm{V}^{2+}-\mathrm{Si}(111)$ surface and was confirmed by SEM measurements. Figure 6 shows SEM images of the (a) $\mathrm{Pt}-$ EBTEA - and (b) $\mathrm{Pt}-\mathrm{V}^{2+}-\mathrm{Si}(111)$ surfaces. While bright spots of 1-10 nm due to the Pt particles were observed at the Pt-EBTEA-Si(111) surface, no such spot was observed at the $\mathrm{Pt}-\mathrm{V}^{2+}-\mathrm{Si}(111)$ surface, despite the existence of platinum as confirmed by XPS (Figure 5b). These results show that the Pt particles at the $\mathrm{Pt}-\mathrm{V}^{2+}-\mathrm{Si}(111)$ surface were smaller than those of the Pt-EBTEA-Si(111) surface and were less than the resolution of the SEM $(\sim 1-2 \mathrm{~nm})$.

The difference in the size of $\mathrm{Pt}$ particles at the $\mathrm{Pt}-\mathrm{V}^{2+}-\mathrm{Si}(111)$ and $\mathrm{Pt}-\mathrm{EBTEA}-\mathrm{Si}(111)$ surfaces can be explained by considering the position of the adsorbed $\mathrm{PtCl}_{4}{ }^{2-}$ as follows. In the present work, platinum particles were formed by two steps: replacement of halogen ions with $\mathrm{PtCl}_{4}{ }^{2-}$ followed by the reduction of the attached $\mathrm{PtCl}_{4}{ }^{2-}$ by $\mathrm{H}_{2}$ gas. While $\mathrm{PtCl}_{4}{ }^{2-}$ on the EBTEA-Si(111) surface is expected to be located outside the molecular layer and, therefore, the growth of Pt to a larger Pt particle $(1-10 \mathrm{~nm})$ should be relatively easy, $\mathrm{PtCl}_{4}{ }^{2-}$ should be confined around the viologen groups within the molecular layer in the case of the $\mathrm{V}^{2+}-\mathrm{Si}(111)$ surface as shown in Scheme 1, and the growth of Pt to a larger Pt particle $(1-10 \mathrm{~nm})$ should be difficult, resulting in the formation of a very small Pt particle $(\sim 1 \mathrm{~nm})$.

Electrochemical Characteristics of Viologen Moieties of the $\mathrm{V}^{2+}-, 3 \mathrm{~L}-\mathrm{V}^{2+}-$, and $5 \mathrm{~L}-\mathrm{V}^{2+}-\mathrm{Si}(111)$ Electrodes. Figure 7a shows the $\mathrm{CV}$ s of the $\mathrm{EBC}, \mathrm{V}^{2+}, 3 \mathrm{~L}-\mathrm{V}^{2+}$, and $5 \mathrm{~L}-\mathrm{V}^{2+} \mathrm{n}$-type $\mathrm{Si}(111)$ electrodes measured in a $0.1 \mathrm{M} \mathrm{Na}_{2} \mathrm{SO}_{4}$ aqueous solution at a scan rate of $50 \mathrm{mV} \mathrm{s}^{-1}$. Two cathodic peaks were observed around -0.50 and $-0.85 \mathrm{~V}$ corresponding to $\mathrm{V}^{2+} / \mathrm{V}^{\cdot+}$ and $\mathrm{V}^{\bullet+}$ / $\mathrm{V}^{+}$, respectively, at the $\mathrm{V}^{2+}-, 3 \mathrm{~L}-\mathrm{V}^{2+}-$, and $5 \mathrm{~L}-\mathrm{V}^{2+}-\mathrm{Si}(111)$ electrodes, whereas no peak was observed at the $\mathrm{EBC}-\mathrm{Si}(111)$ electrode. Anodic peaks of viologen moieties are somewhat smaller than the corresponding cathodic peaks, reflecting the fact that the majority carrier is electron and the anodic process is inhibited at an n-type semiconductor electrode.

Surface concentrations of electroactive viologen moieties at the $\mathrm{V}^{2+}-, 3 \mathrm{~L}-\mathrm{V}^{2+}-$, and $5 \mathrm{~L}-\mathrm{V}^{2+}-\mathrm{Si}(111)$ electrodes were estimated from the charge obtained by integrating the cathodic peak (open circles) of the first CV to be $3.1 \times 10^{-10}, 8.9 \times$ $10^{-10}$, and $1.4 \times 10^{-9} \mathrm{~mol} \mathrm{~cm}^{-2}$, respectively, and linearly increased with number of viologen layers by ca. $2.8 \times 10^{-10}$ $\mathrm{mol} \mathrm{cm}-2$ per layer as shown in Figure $7 \mathrm{~b}$. Ellipsometric thickness of the molecular layer at the $\mathrm{EBC}-, \mathrm{V}^{2+}-, 3 \mathrm{~L}-\mathrm{V}^{2+}-$, and $5 \mathrm{~L}-\mathrm{V}^{2+}-\mathrm{Si}(111)$ surfaces also linearly increased with the number of layers, as shown in Figure 7b. These results show that the formation of the multiviologen layer proceeded in layerby-layer fashion with almost $100 \%$ yield and all viologen groups in the molecular layers are electroactive. The amount of viologen moiety per layer is a little smaller than the maximum coverage estimated from the surface-projected size of the perpendicularly oriented bipyridyl group, $3.7 \times 10^{-10} \mathrm{~mol} \mathrm{~cm}{ }^{-2} .70$

Although viologen multilayers have been previously constructed on gold ${ }^{71,72}$ and silicon ${ }^{58}$ substrates by using viologen molecules with two alkyl thiol and two alkyl trimethoxysilyl groups, respectively, at both ends, the present multilayer formation process is far better controlled than these cases where multilayers are formed via intermolecular disulfide formation or condensation of trimethoxysilyl groups, which takes place randomly at any molecule with free thiol or trimethoxysilyl groups both at the surface and in the solution. The strategy of layer-by-layer growth can be also used for other tailor-made multifunctional layers by choosing appropriate molecules as building blocks.

Electrochemical Hydrogen Evolution at Modified $n$ Si(111) Electrodes in the Dark. Figure 8 shows quasi-steadystate current-voltage $(I-V)$ curves obtained in the dark with a very slow scan rate $\left(1 \mathrm{mV} \mathrm{s}^{-1}\right)$ in a $0.1 \mathrm{M} \mathrm{Na}_{2} \mathrm{SO}_{4}$ aqueous solution at an n-type $\mathrm{Si}(111)$ electrode after each modification step. At the $\mathrm{H}-\mathrm{Si}(111)$ electrode, the cathodic current started to flow from around $-0.6 \mathrm{~V}$. Since steady current was observed, 
(a)

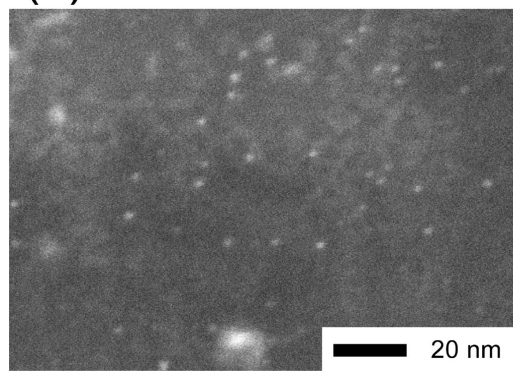

(b)

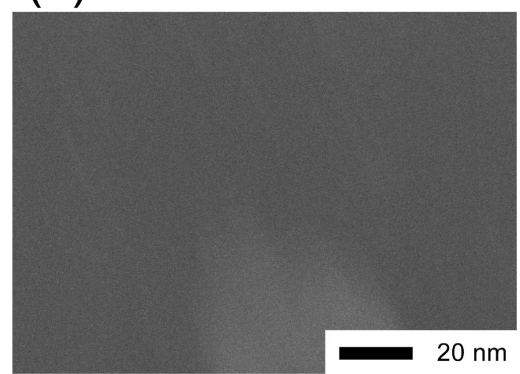

Figure 6. SEM images of the (a) $\mathrm{Pt}-\mathrm{EBTEA}-\mathrm{Si}(111)$ and (b) $\mathrm{Pt}-\mathrm{V}^{2+}-\mathrm{Si}(111)$ surfaces.
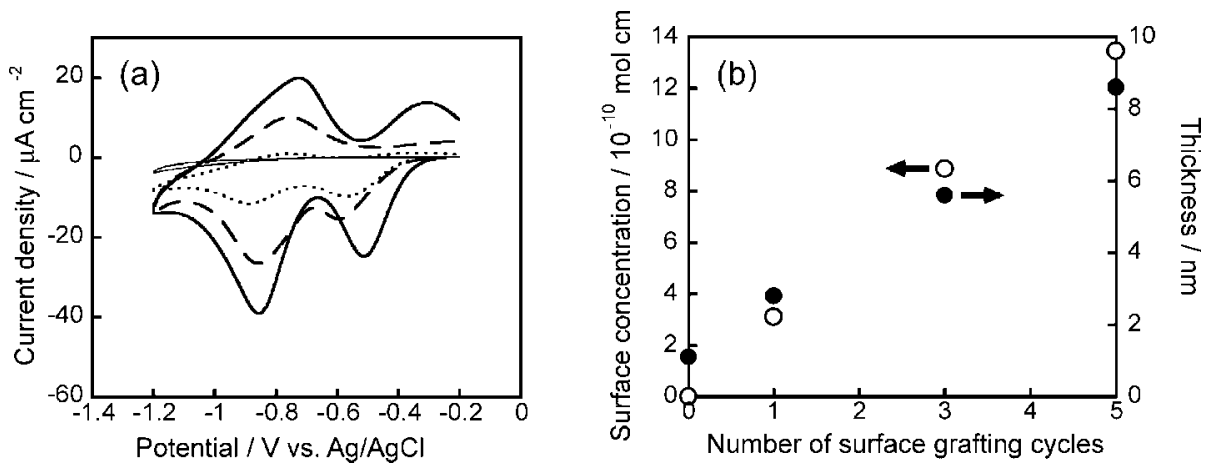

Figure 7. (a) Cyclic voltammograms of the $\mathrm{n}$-type $\mathrm{EBC}-$ (thin solid line), $\mathrm{V}^{2+}-$ (dotted line), $3 \mathrm{~L}-\mathrm{V}^{2+}-\left(\right.$ dashed line), and $5 \mathrm{~L}-\mathrm{V}^{2+}-\mathrm{Si}(111)$ electrodes (bold solid line) in $0.1 \mathrm{M} \mathrm{Na}_{2} \mathrm{SO}_{4}$ aqueous solution with a scan rate of $50 \mathrm{mV} \mathrm{s}^{-1}$. (b) Surface concentrations of the viologen moiety and ellipsometric thickness as a function of the numbers of layer.

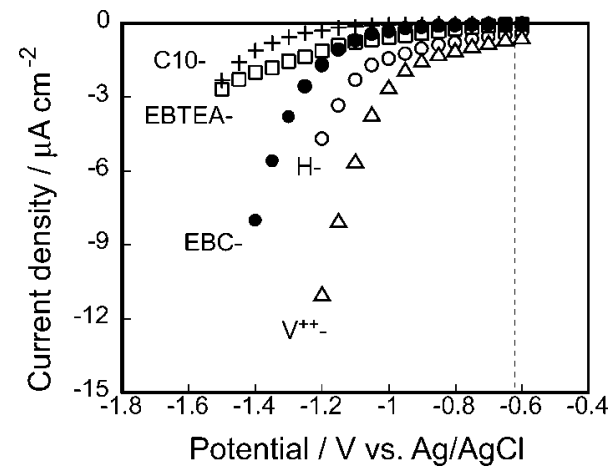

Figure 8. Steady-state $I-V$ curves of the n-type $\mathrm{H}-(\mathrm{O}), \mathrm{EBC}-(\bullet)$, EBTEA $-(\square), \mathrm{V}^{2+}-(\Delta)$, and $\mathrm{C} 10-\mathrm{Si}(111)(+)$ electrodes in $0.1 \mathrm{M}$ $\mathrm{Na}_{2} \mathrm{SO}_{4}$ aqueous solution in the dark. The dotted line shows the reversible potential of $\mathrm{H}^{+} / \mathrm{H}_{2}$.

the current should be due to HER. At the EBC-Si(111) electrode, the HER current started to flow at more negative potential than at the $\mathrm{H}-\mathrm{Si}(111)$ electrode and the $I-V$ curve shifted negatively by about $0.1 \mathrm{~V}$, showing that the EBC layer acts as an electron transfer barrier. Although an additional layer was attached and thickness of the molecular layer increased by ca. $1.7 \mathrm{~nm}$, the HER rate at the $\mathrm{V}^{2+}-\mathrm{Si}(111)$ electrode was increased and the $I-V$ curve shifted positively by 0.1 and 0.2 $\mathrm{V}$ from the ones at the $\mathrm{H}-\mathrm{Si}(111)$ and $\mathrm{EBC}-\mathrm{Si}(111)$ electrodes, respectively. On the other hand, the HER rate at the EBTEA-Si(111) electrode became significantly slower than the ones at the $\mathrm{H}-\mathrm{Si}(111)$ and EBC-Si(111) electrodes, showing that the electroinactive EBTEA moiety acts as a more effective barrier. These results suggest that the electron transfer was mediated by the viologen moiety in the organic monolayer. A much smaller current was observed at the $\mathrm{C} 10-\mathrm{Si}(111)$ electrode because the barrier is thicker than the EBTEA-Si(111) and the alkyl chain is more insulating than the aromatic group.
Figure 9 shows quasi-steady-state $I-V$ curves of the n-type EBTEA-, Pt-EBTEA-, $\mathrm{V}^{2+}-, \mathrm{Pt}-\mathrm{V}^{2+}-, 3 \mathrm{~L}-\mathrm{Pt}-\mathrm{V}^{2+}-$, and $5 \mathrm{~L}-\mathrm{Pt}-\mathrm{V}^{2+}-\mathrm{Si}(111)$ electrodes obtained in the dark with very slow scan rate $\left(1 \mathrm{mV} \mathrm{s}^{-1}\right)$ in a $0.1 \mathrm{M} \mathrm{Na}_{2} \mathrm{SO}_{4}$ aqueous solution. The $I-V$ curve shifted in a positive direction by 0.2 and $0.5 \mathrm{~V}$ at the EBTEA- and $\mathrm{V}^{2+}-\mathrm{Si}(111)$ electrode by platinum deposition on surfaces, proving that the Pt particles on the $\mathrm{Si}(111)$ surfaces served as a catalyst for HER. A potential shift by $\mathrm{Pt}$ deposition at the $\mathrm{V}^{2+}-\mathrm{Si}(111)$ electrode larger than that at the EBTEA-Si(111) electrode also proved the electron transfer mediation capability of the viologen moiety. At the $\mathrm{Pt}-\mathrm{V}^{2+}-\mathrm{Si}(111)$ electrodes, electrons are used to reduce viologen moiety and reduced viologen was oxidized to viologen by $\mathrm{H}^{+}$with Pt catalyst because the redox potential of $\mathrm{V}^{2+} / \mathrm{V}^{*+}$ is more negative than that of $\mathrm{H}^{+} / \mathrm{H}_{2}$, resulting in the hydrogen evolution as shown by the following equations.

$$
\begin{gathered}
\mathrm{V}^{2+}+\mathrm{e}^{-} \rightarrow \mathrm{V}^{+} \\
2 \mathrm{~V}^{\bullet+}+2 \mathrm{H}^{+} \rightarrow \mathrm{H}_{2}
\end{gathered}
$$

Thus, the viologen moiety acts as an electron-transfer mediator for hydrogen evolution reaction at the Pt nanoparticles. On the other hand, electrons must tunnel through the electroinactive barrier layer at the $\mathrm{Pt}-\mathrm{EBTEA}-\mathrm{Si}(111)$ electrode to the Pt catalyst, resulting in the relatively slow HER rate. In addition, the extremely small size of the Pt nanoparticles formed at the $\mathrm{Pt}-\mathrm{V}^{2+}-\mathrm{Si}(111)$ may play an important role in high catalytic activity for HER. Furthermore, the $\mathrm{Pt}-\mathrm{V}^{2+}-\mathrm{Si}(111)$ electrode was stable as the HER current at $-0.9 \mathrm{~V}$ remained constant even after the potential was scanned between -0.9 and -0.1 $\mathrm{V}$ five times. One reason for this stability should be because the Pt nanoparticles were present within the molecular layer with low mobility.

The $I-V$ curve shifted positively (i.e., HER rate increased) as the number of the viologen/Pt layers increased. This shows 


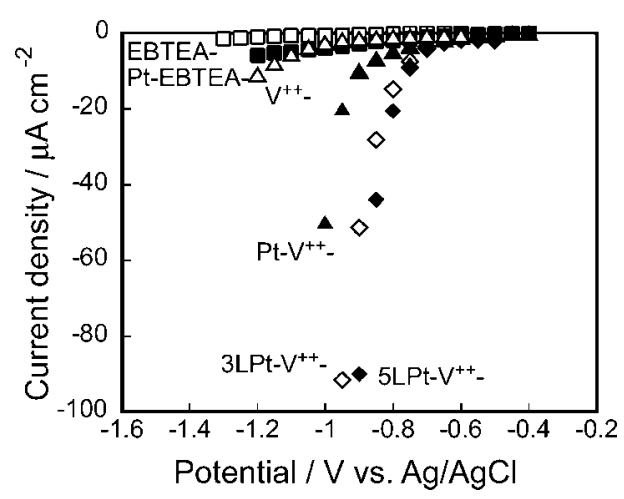

Figure 9. Steady-state $I-V$ curves of the n-type EBTEA- $(\square)$, $\mathrm{Pt}-$ EBTEA $-(\mathbf{\square}), \mathrm{V}^{2+}-(\Delta), \mathrm{Pt}-\mathrm{V}^{2+}-(\mathbf{\Delta}), 3 \mathrm{~L}-\mathrm{Pt}-\mathrm{V}^{2+}-(\diamond)$, and $5 \mathrm{~L}-\mathrm{Pt}-\mathrm{V}^{2+}-\mathrm{Si}(111)(\diamond)$ electrodes in the dark in $0.1 \mathrm{M} \mathrm{Na}_{2} \mathrm{SO}_{4}$ aqueous solution.

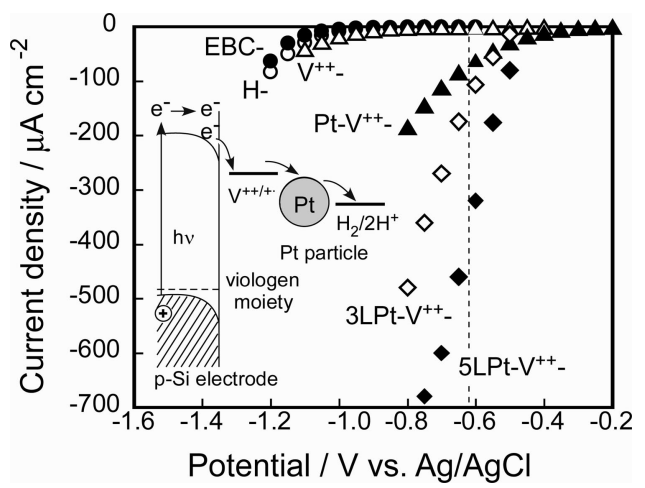

Figure 10. Steady-state $I-V$ curves of the p-type $H-(O)$, EBC$(\bullet), \mathrm{V}^{2+}-(\Delta), \mathrm{Pt}^{-} \mathrm{V}^{2+}-(\boldsymbol{\Delta}), 3 \mathrm{~L}-\mathrm{Pt}-\mathrm{V}^{2+}-(\diamond)$, and $5 \mathrm{~L}-\mathrm{Pt}-\mathrm{V}^{2+}-$ $\mathrm{Si}(111)(\diamond)$ electrodes under photoillumination in $0.1 \mathrm{M} \mathrm{Na}_{2} \mathrm{SO}_{4}$ aqueous solution. Inset: Energy diagram for the hydrogen evolution reaction at the $\mathrm{p}-\mathrm{Si}(111)$ modified with $\mathrm{Pt} / \mathrm{viologen}$ layers. The dotted line shows the reversible potential of $\mathrm{H}^{+} / \mathrm{H}_{2}$.

that the Pt particles dispersed within the viologen multilayers effectively acted as the HER catalyst although the distance from the electrode to the Pt particles increased with number of layers, confirming that viologen groups within the multilayer formed a network for a supply of electrons from the Si(111) electrode to the Pt particles. Thus, HER is efficiently accelerated at the Pt particles. ${ }^{44}$

Photoelectrochemical Hydrogen Evolution at Modified p-Si(111) Electrodes. Figure 10 shows quasi-steady-state $I-V$ curves of the p-type $\mathrm{H}-, \mathrm{EBC}-, \mathrm{V}^{2+}-, \mathrm{Pt}-\mathrm{V}^{2+}-, 3 \mathrm{~L}-$ $\mathrm{Pt}-\mathrm{V}^{2+}-$, and $5 \mathrm{~L}-\mathrm{Pt}-\mathrm{V}^{2+}-\mathrm{Si}(111)$ electrodes under illumination obtained with a very slow scan rate $\left(1 \mathrm{mV} \mathrm{s}^{-1}\right)$ in a $0.1 \mathrm{M}$ $\mathrm{Na}_{2} \mathrm{SO}_{4}$ aqueous solution. Similar to the results at the n-Si electrode in the dark, the HER current started to flow at a more negative potential at the $\mathrm{EBC}-\mathrm{Si}(111)$ electrode but at more positive potential at the $\mathrm{V}^{2+}-\mathrm{Si}(111)$ electrode than at the $\mathrm{H}-\mathrm{Si}(111)$ electrode, showing that the EBC layer and $\mathrm{V}^{2+}$ moiety act as a barrier and a mediator, respectively, for the photoexcited electron-transfer $\mathrm{p}$-Si(111) electrode. A significant positive shift of the $I-V$ curve was observed by the viologen/ Pt modification, indicating photoelectrochemical HER was also enhanced by this modification. Cathodic current due to photoelectrochemical HER was observed even at potentials more positive than the reversible potential of $\mathrm{H}^{+} / \mathrm{H}_{2}$. Enhancement of photoelectrochemical HER on a Si electrode by viologen/Pt modification was reported by Wrighton and his colleagues more than 25 years ago. ${ }^{58}$ They utilized condensation reaction of two alkyl trimethoxysilyl groups of viologen molecules to form a viologen polymer layer, and $\mathrm{Pt}$ was incorporated in a molecular layer by a method similar to that used in the present work (i.e., ion exchange by $\mathrm{PtCl}_{6}{ }^{4-}$ followed by electrochemical reduction in Pt ion-free solution). They reported about a $500 \mathrm{mV}$ positive shift of $I-V$ relation by the viologen/Pt modification, whereas about 500, 570, and $650 \mathrm{mV}$ shifts were observed for $\mathrm{Pt}-\mathrm{V}^{2+}$, $3 \mathrm{~L}-\mathrm{Pt}-\mathrm{V}^{2+}$, and $5 \mathrm{~L}-\mathrm{Pt}-\mathrm{V}^{2+}$ modifications, respectively. The amount of $\mathrm{Pt}$ incorporated in the molecular layer estimated from the surface concentration of viologen groups of the present system even in the $5 \mathrm{~L}-\mathrm{Pt}-\mathrm{V}^{2+}$ layer was $5 \times 10^{-9} \mathrm{~mol} / \mathrm{cm}^{-2}$, which is 1 order of magnitude less than that of Wrigton's system $\left(5 \times 10^{-8}\right)$. Thus, one can conclude that the well-ordered viologen/Pt particle multilayer network constructed in the present work provides a more efficient electrode for photoelectrochemical HER.

\section{Conclusions}

Mono- and multiviologen layers were constructed on hydrogenterminated $\mathrm{Si}(111)$ surfaces via a $\mathrm{Si}-\mathrm{C}$ bond in a layer-bylayer fashion, and electron mediation capability of the viologen moiety was demonstrated. Very small, well-dispersed Pt particles were formed within the viologen layers by ion exchange of halide ions by $\mathrm{PtCl}_{4}{ }^{2-}$ followed by reduction hydrogen gas. Electrochemical HER rates in the dark and under illumination were significantly enhanced by the $\mathrm{Pt}$ deposition. HER rate increased with the increase of the number of viologen/Pt layers, showing that all attached viologen moieties and Pt particles served as electron mediator and catalyst for HER, respectively.

Acknowledgment. The present work was partially supported by a Grant-in-Aid for Scientific Research (A) (2006-2009, No. 18205016), the Promotion of Novel Interdisciplinary Fields Based on Nanotechnology and Materials, and the Global COE Program (Project No. B01: Catalysis as the Basis for Innovation in Material Science), from the Ministry of Education, Culture, Sports, Science and Technology. Mr. Kitazawa of Shin-Etsu Semiconductor is acknowledged for the donation of the $\operatorname{Si}(111)$ wafers. We thank Prof. Ijiro and Dr. Sawadaishi for their help with the SEM measurement.

\section{References and Notes}

(1) Ulmann, A. An Introduction to Ultrathin Organic Films from Langmuir-Blodgett to Self-Assembly; Academic Press: New York, 1991.

(2) Uosaki, K.; Kondo, T.; Zhang, X. Q.; Yanagida, M. J. Am. Chem. Soc. 1997, 119, 8367-8368.

(3) Yamada, R.; Uosaki, K. Langmuir 1998, 14, 855-861.

(4) Yamada, R.; Uosaki, K. Langmuir 1997, 13, 5218-5221.

(5) Finklea, H. O. In Electroanalytical Chemistry: A Series of Advances; Bard, A. J., Rubinstein, I., Eds.; Dekker: New York, 1996; Vol. 19, pp 109-335.

(6) Love, J. C.; Estroff, L. A.; Kriebel, J. K.; Nuzzo, R. G.; Whitesides, G. M. Chem. Rev. 2005, 105, 1103-1169.

(7) Uosaki, K.; Sato, Y.; Kita, H. Langmuir 1991, 7, 1510-1514.

(8) Kondo, T.; Uosaki, K. J. Photochem. Photobiol., C 2007, 8, 1-17.

(9) Gorman, C. B.; Carroll, R. L.; Fuierer, R. R. Langmuir 2001, 17, 6923-6930.

(10) Rohde, R. D.; Agnew, H. D.; Yeo, W. S.; Bailey, R. C.; Heath, J. R. J. Am. Chem. Soc. 2006, 128, 9518-9525.

(11) Faber, E. J.; Sparreboom, W.; Groeneveld, W.; de Smet, L. C. P. M.; Bomer, J.; Olthuis, W.; Zuilhof, H.; Sudholter, E. J. R.; Bergveld, P.; van den Berg, A. ChemPhys Chem 2007, 8, 101-112.

(12) Fabre, B.; Lopinski, G. P.; Wayner, D. D. M. J. Phys. Chem. B 2003, 107, 14326-14335.

(13) Nakato, K.; Takabayashi, S.; Imanishi, A.; Murakoshi, K.; Nakato, Y. Sol. Energy Mater. Sol. Cells 2004, 83, 323-330.

(14) Takabayashi, S.; Ohashi, M.; Mashima, K.; Liu, Y.; Yamazaki, S.; Nakato, Y. Langmuir 2005, 21, 8832-8838.

(15) Ohashi, M.; Takabayashi, S.; Mashima, K.; Nakato, Y. Chem. Lett. 2006, 35, 956-957. 
(16) Cai, W.; Peck, J. R.; van der Weide, D. W.; Hamers, R. J. Biosens. Bioelectron. 2004, 19, 1013-1019.

(17) Linford, M. R.; Chidsey, C. E. D. J. Am. Chem. Soc. 1993, 115, 12631-12632.

(18) Linford, M. R.; Fenter, P.; Eisenberger, P. M.; Chidsey, C. E. D. J. Am. Chem. Soc. 1995, 117, 3145-3155.

(19) Boukherroub, R.; Morin, S.; Bensebaa, F.; Wayner, D. D. M. Langmuir 1999, 15, 3831-3835.

(20) Yu, H. Z.; Morin, S.; Wayner, D. D. M.; Allongue, P.; de Villeneuve, C. H. J. Phys. Chem. B 2000, 104, 11157-11161.

(21) Quayum, M. E.; Kondo, T.; Nihonyanagi, S.; Miyamoto, D.; Uosaki,

K. Chem. Lett. 2002, 31, 208.

(22) Uosaki, K.; Quayum, M. E.; Nihonyanagi, S.; Kondo, T. Langmuir 2004, 20, 1207-1212.

(23) Nihonyanagi, S.; Miyamoto, D.; Idojiri, S.; Uosaki, K. J. Am. Chem. Soc. 2004, 126, 7034-7040.

(24) Terry, J.; Linford, M. R.; Wigren, C.; Cao, R. Y.; Pianetta, P.; Chidsey, C. E. D. Appl. Phys. Lett. 1997, 71, 1056-1058.

(25) Effenberger, F.; Gotz, G.; Bidlingmaier, B.; Wezstein, M. Angew. Chem., Int. Ed. 1998, 37, 2462-2464.

(26) deVilleneuve, C. H.; Pinson, J.; Bernard, M. C.; Allongue, P. J. Phys. Chem. B 1997, 101, 2415-2420. L10.

(27) Fidelis, A.; Ozanam, F.; Chazalviel, J. N. Surf. Sci. 2000, 444, L7-

(28) Takakusagi, S.; Miyasaka, T.; Uosaki, K. J. Electroanal. Chem. 2007, 599, 344-348.

(29) Buriak, J. M.; Allen, M. J. J. Am. Chem. Soc. 1998, 120, 13391340 .

(30) Buriak, J. M.; Stewart, M. P.; Geders, T. W.; Allen, M. J.; Choi, H. C.; Smith, J.; Raftery, D.; Canham, L. T. J. Am. Chem. Soc. 1999, 121, 11491-11502.

(31) Bansal, A.; Li, X. L.; Lauermann, I.; Lewis, N. S.; Yi, S. I.; Weinberg, W. H. J. Am. Chem. Soc. 1996, 118, 7225-7226.

(32) Bansal, A.; Lewis, N. S. J. Phys. Chem. B 1998, 102, 1067-1070.

(33) Gerischer, H. In Advances in Electrochemistry and Electrochemical Engineering; Delahay, P., Tobias, C. W., Eds.; Interscience: New York, 1961.

(34) Pleskov, Y. V.; Gurevich, Y. Y. Semiconductor Photoelectrochemistry; Consultants Bureau: New York, 1986.

(35) Bockris, J. O.; Uosaki, K. J. Electrochem. Soc. 1977, 124, 1348 1355 .

(36) Nakato, Y.; Tonomura, S.; Tsubomura, H. Ber. Bunsen.-Ges. Phys. Chem. 1976, 80, 1289

(37) Heller, A.; Aharonshalom, E.; Bonner, W. A.; Miller, B. J. Am Chem. Soc. 1982, 104, 6942-6948.

(38) Aspnes, D. E.; Heller, A. J. Phys. Chem. 1983, 87, 4919-4929.

(39) Fan, F. R. F.; Keil, R. G.; Bard, A. J. J. Am. Chem. Soc. 1983, 105, 220-224.

(40) Fan, F. R. F.; Shea, T. V.; Bard, A. J. J. Electrochem. Soc. 1984 $131,828-833$.

(41) Nakato, Y.; Tsubomura, H. J. Photochem. 1985, 29, 257-266.

(42) Porter, J. D.; Heller, A.; Aspnes, D. E. Nature 1985, 313, 664 666.

(43) Meier, A.; Uhlendorf, I.; Meissner, D. Electrochim. Acta 1995, 40, $1523-1535$.
(44) Nakato, Y.; Yano, H.; Nishiura, S.; Ueda, T.; Tsubomura, H. J. Electroanal. Chem. 1987, 228, 97-108.

(45) Nakato, Y.; Tsubomura, H. Electrochim. Acta 1992, 37, 897-907.

(46) Nakato, Y.; Ueda, K.; Yano, H.; Tsubomura, H. J. Phys. Chem. 1988, 92, 2316-2324.

(47) Nakato, Y.; Ueda, K.; Tsubomura, H. J. Phys. Chem. 1986, 90 , 5495-5496.

(48) Uosaki, K.; Kita, H. Chem. Lett. 1984, 953-956.

(49) Kaneko, S.; Uosaki, K.; Kita, H. J. Phys. Chem. 1986, 90, 66546657.

(50) Bookbinder, D. C.; Lewis, N. S.; Bradley, M. G.; Bocarsly, A. B.; Wrighton, M. S. J. Am. Chem. Soc. 1979, 101, 7721-7723.

(51) Fan, F. R. F.; Reichman, B.; Bard, A. J. J. Am. Chem. Soc. 1980, $102,1488-1492$.

(52) Wrighton, M. S.; Austin, R. G.; Bocarsly, A. B.; Bolts, J. M.; Haas, O.; Legg, K. D.; Nadjo, L.; Palazzotto, M. C. J. Am. Chem. Soc. 1978, $100,1602-1603$

(53) Bolts, J. M.; Bocarsly, A. B.; Palazzotto, M. C.; Walton, E. G.; Lewis, N. S.; Wrighton, M. S. J. Am. Chem. Soc. 1979, 101, 1378-1385.

(54) Bookbinder, D. C.; Bruce, J. A.; Dominey, R. N.; Lewis, N. S.; Wrighton, M. S. Proc. Natl. Acad. Sci. U.S.A. 1980, 77, 6280-6284.

(55) Bookbinder, D. C.; Wrighton, M. S. J. Am. Chem. Soc. 1980, 102, $5123-5125$.

(56) Bookbinder, D. C.; Lewis, N. S.; Wrighton, M. S. J. Am. Chem. Soc. 1981, 103, 7656-7659.

(57) Bruce, J. A.; Wrighton, M. S. Isr. J. Chem. 1982, 22, 184-189.

(58) Dominey, R. N.; Lewis, N. S.; Bruce, J. A.; Bookbinder, D. C.;

Wrighton, M. S. J. Am. Chem. Soc. 1982, 104, 467-482.

(59) Bruce, J. A.; Murahashi, T.; Wrighton, M. S. J. Phys. Chem. 1982, $86,1552-1563$.

(60) Masuda, T.; Uosaki, K. Chem. Lett. 2004, 33, 788-789.

(61) Higashi, G. S.; Chabal, Y. J.; Trucks, G. W.; Raghavachari, K. Appl. Phys. Lett. 1990, 56, 656-658.

(62) Ye, S.; Ichihara, T.; Uosaki, K. Appl. Phys. Lett. 1999, 75, 15621564

(63) Monk, P. M. S. The Viologens: Physicochemical Properties, Synthesis and Applications of the Salts of 4,4'-Bipyridine; Wiley: New York, 1998

(64) Azzam, R. M.; Bashara, N. M. Ellipsometry and Polarized Light; North-Holland: Amsterdam, 1977.

(65) Shi, J.; Hong, B.; Parikh, A. N.; Collins, R. W.; Allara, D. L. Chem.

Phys. Lett. 1995, 246, 90-94.

(66) Uosaki, K.; Kondo, T.; Okamura, M.; Song, W. B. Faraday Discuss. 2002, 121, 373-389.

(67) Minko, S.; Patil, S.; Datsyuk, V.; Simon, F.; Eichhorn, K. J.; Motornov, M.; Usov, D.; Tokarev, I.; Stamm, M. Langmuir 2002, 18, 289296.

(68) Muilenberg, G. E. Handbook of X-Ray Photoelectron Spectroscopy; Perkin-Elmer: Eden Prairie, MN, 1978.

(69) Marcus, P.; Hinnen, C. Surf. Sci. 1997, 392, 134-142.

(70) Widrig, C. A.; Majda, M. Langmuir 1989, 5, 689-695.

(71) Raymo, F. M.; Alvarado, R. J.; Pacsial, E. J.; Alexander, D. J. Phys. Chem. B 2004, 108, 8622-8625.

(72) Alvarado, R. J.; Mukherjee, J.; Pacsial, E. J.; Alexander, D.; Raymo, F. M. J. Phys. Chem. B 2005, 109, 6164-6173.

JP8006188 